\title{
26 Research Square \\ Antiviral functions of type I and type III interferons in the olfactory epithelium
}

\author{
Ahmad Zedan \\ University of California Davis \\ Ashley D. Winters \\ University of California Davis \\ Wei Yu \\ Xi'an Medical University \\ Shuangyan Wang \\ Qingdao University School of Basic Medicine \\ Ashley Takeshita \\ University of California Davis \\ Qizhi Gong ( $\nabla$ qzgong@ucdavis.edu ) \\ University of California Davis, School of Medicine https://orcid.org/0000-0002-7453-6508
}

\section{Research}

Keywords: Olfactory sensory neurons, neuroinflammation, viral infection, interferon, innate immune

Posted Date: June 24th, 2020

DOI: https://doi.org/10.21203/rs.3.rs-36665/v1

License: (c) (i) This work is licensed under a Creative Commons Attribution 4.0 International License.

Read Full License 


\section{Abstract}

\section{Background}

The olfactory epithelium (OE) is one of the few sites where environmental pathogens can gain direct access to the brain. Despite this vulnerable arrangement, little is known about the protective mechanisms in the $\mathrm{OE}$ to prevent viral infection and subsequent entry into the brain.

\section{Methods}

We systematically investigated acute responses in the olfactory mucosa (OM) upon exposure to vesicular stomatitis virus (VSV) by RNA-sEq. VSVs were nasally inoculated into C57BL/6 mice. OM were dissected for gene expression analysis at different time points after viral inoculation. Interferon functions were determined by comparing viral gene expression in interferon (Ifn) receptor knockout (Ifnar ${ }^{-/-}$and IfnIr $1^{-/}$ -) with wildtype OM.

Results

Antiviral responses were observed as early as $24 \mathrm{hrs}$ post viral exposure in the OM. Amongst the rapidly upregulated transcripts observed were specific type I as well as type III Ifns and interferon stimulated genes. Genetic analyses demonstrated that both type I and type III IFN signaling are required for the suppression of viral replication in the OM. Nasal IFNb1 or IFNI2 administration effectively reduces viral load in the OM.

Conclusions:

OE possesses innate ability to respond and suppress viral infection. Type I and type III IFNs actively participate in the OE's antiviral functions. Nasal IFN application effectively blocks viral replication in the OE suggesting therapeutic potential against viral insult.

\section{Introduction}

The olfactory neuroepithelium (OE) is one of the few neural tissues that directly interact with the environment. Olfactory mucosa (OM) located posteriorly in the nasal cavity consists of $\mathrm{OE}$ and underlining lamina propria [1]. OE is a pseudostratified epithelium consisting of sustentacular (Sus) cells, olfactory sensory neurons (OSNs), neuroprogenitors, basal cells and other non-neuronal cell types. Sus cells in the OE are located superficially to form a protective sheet. OSNs are bipolar neurons with an apical dendritic process extending through the Sus cell layer. The dendritic endings provide anchors for ciliary processes which spread to cover the surface of the OE [2-5]. Therefore, both Sus cells and OSNs are constantly exposed to potential environmental insults at the epithelial surface.

OSN axons, forming the olfactory nerve, connect the periphery to the olfactory bulb (OB) of the brain. Intranasal inoculations of several types of neurotrophic viruses, including influenza A virus, herpes 
simplex virus, hepatitis coronavirus and vesicular stomatitis virus (VSV) are shown to infect OSNs and travel along the olfactory nerve to reach the brain [6-11]. Viral infection of the central nervous system (CNS) has dire consequences and often results in neuroinflammation, neuropathogenesis and encephalitis $[7,12,13]$. Activation of astrocytes and microglia in the OB mount antiviral responses to prevent viral replication and viral spread into other regions of the brain [13-15].

While it is recognized that the $\mathrm{OB}$ can effectively curb viral replication and limit further spread into the CNS, it is not clear whether $\mathrm{OE}$, which directly interfaces with external environmental pathogens, mounts an effective innate immune response $[14,16]$. Neurons of the CNS have to carefully maintain a balance between inflammatory responses and suppression of cytolytic activity in order to protect neurons from viral-induced damage [17]. However, albeit being a neuronal tissue, OE has a unique capacity for neurogenesis making cell death a possible strategy for controlling viral infection [18]. Recruitment of phagocytic macrophages and apoptosis of OSNs were observed following pathogen challenge in the OE [19-21]. In addition, cytokine signaling was shown to participant in controlling viral infection in teleost fish OSNs as well as in mice [22, 23].

Activation of an acute innate immune response is important in inhibiting viral replication and preventing viral spread. Though a few selected cytokines and signaling pathways have been characterized, systematic analysis for acute response to viral infection in the $O E$ is still lacking $[20,22,24,25]$. In this study, we characterized transcription profile changes in the OE during acute phase of VSV infection. Further characterization of cytokine and chemokine regulations revealed that both type I and type III interferon signaling are actively involved in antiviral responses in the $\mathrm{OE}$ in a cell type specific manner.

\section{Methods}

\section{Animals}

Adult C57BL/6J mice were obtained from Charles River Laboratories (Wilmington, Massachusetts). Ifn/r1 knockout mice (Ifn/r $1^{-/-}$) were kindly provided by Dr. Herbert Virgin [26]. Ifnar1 knockout mice (Ifnar ${ }^{-/-}$) were acquired from MMRRC (B6.129S2-Ifnar1tm1Agt/Mmjax \#32045-Jax). Stat1 knockout mice (Stat1 ${ }^{-1}$ -) were obtained from Jackson Laboratory (B6.129S(Cg)-Stat1 tm1Dlv/J \#12606). All procedures were performed according to $\mathrm{NIH}$ guidelines and approved by UC Davis Animal Care and Use Committee.

\section{VSV nasal instillation}

The original stock of VSV-12'GFP was kindly provided by Dr. Anthony van den Pol. This highly attenuated strain has two GFP genes inserted at the 3 ' end of the viral genome, greatly reducing VSV replication, but having no impact on the effectiveness in generating an immune response [27]. VSV-12'GFP were produced in BHK21 cells, concentrated and purified into phosphate buffered saline (PBS). Viral titers were determined by plaque assays $[13,26]$. For nasal instillation, animals were anesthetized deeply by isoflurane. VSV-12'GFP was instilled into the nasal cavity by placing drops of virus at the nostril and allowing them to enter into the nasal cavity by inhalation. Twenty microliters of $10^{5} \mathrm{pfu} / \mu \mathrm{l}$ virus was 
applied to each nostril, for a total of $40 \mu \mathrm{l}$ per animal. Similarly, PBS was administered to littermates as a vehicle control. We define acute phase of viral exposure in this study as within 48hrs. Biological triplicates from $3 \mathrm{hr}, 6 \mathrm{hr}, 12 \mathrm{hr}, 24 \mathrm{hr}$, and $48 \mathrm{hr}$ post viral instillation (PI) time points were collected.

To provide exogenous IFNs intranasally, $25 \mu \mathrm{l}(12.5 \mu \mathrm{l}$ for each nostril) of $40 \mathrm{ng} / \mu \mathrm{l}$ recombinant IFN $\beta 1$ (R\&D, 8234-MB-010/CF) or IFN $\lambda 2$ (R\&D, 4635-ML-025/CF) was given to mice one hour before VSV administration ( $20 \mu \mathrm{l}$ of $10^{5} \mathrm{pfu} / \mu \mathrm{l} \mathrm{VSV}$ at each nostril). Tissues were collected at $24 \mathrm{hrPI}$ to evaluate exogenous IFN $\beta 1$ and IFN $\lambda 2$ impact on VSV in the OE and OB.

\section{RNA-sequencing}

OM was dissected and homogenized in TriZol with TissueLyzer (Qiagen). Total RNA was extracted and purified with Zymogen RNA clean and concentration kit. 3'-Taq-RNA-seq library was constructed which generates a single initial library molecule per transcript. Biological triplicate samples were included for PBS controls and VSV exposed at $3 \mathrm{hr}, 6 \mathrm{hr}, 9 \mathrm{hr}, 24 \mathrm{hr}$ and $48 \mathrm{hrsPI}$. The libraries were sequenced on Illumina HiSeq 4000 for single-end 90 bp reads. A minimum of 6 million reads were obtained for each sample. After quality control, differential expression analyses were performed following the limma-voom Bioconductor pipeline. Comparison between VSV and PBS at each time point are expressed as Log fold change (LogFC) and adj $P$ values were determined by Benjamini-Hochberg false discovery rate adjusted p-value.

\section{Western Blotting}

OM was dissected and flash frozen in liquid nitrogen. RIPA buffer with cOmplete protease inhibitor was used to lyse the cells. Homogenization was performed using TissueLyzer with $5 \mathrm{~mm}$ stainless steel beads ( $30 \mathrm{~Hz}, 1.5 \mathrm{~min}$ twice). Protein preparations were separated on 12\% SDS-PAGE gel and transferred to a nitrocellulose membrane. Antibodies used were: Rabbit pSTAT1(Ser727) (Abcam ab109461), Rabbit pSTAT2(Tyr689) (Millipore 07-224), Mouse a-tubulin (Active Motif 39528).

\section{Immunohistochemistry}

Mice were perfusion-fixed with $4 \%$ paraformaldehyde followed by immersion post-fixation overnight. $\mathrm{OE}$ and $\mathrm{OB}$ were cryoprotected in $30 \%$ sucrose, embedded in optimal cutting temperature (OCT) compound and sectioned at a thickness of $14 \mu \mathrm{m}$. Antibodies used are: Chicken anti-OMP (custom, 1:1000), Goat anti-GFP (Rockland, 1:500), Rabbit anti-IFNAR1 (Sino Biological, 1:20), Goat anti-IFNLR1 (Novagus, 1:100), Rabbit anti-pSTAT1 (Abcam, 1:100). Images were captured using Olympus FV1000 and FV3000 Confocal.

\section{Quantitative RT-PCR}

$\mathrm{OM}$ and $\mathrm{OB}$ were dissected and flash frozen in liquid nitrogen post viral infection. RNA extractions were performed with Trizol and Zymogen RNA clean and concentrate kit. After reverse transcription with poly deoxythymine (dT) primer, cDNA was used for subsequent real-time PCR reactions. Real-time PCR 
experiments were conducted using SybrGreen chemistry on applied biosystems StepOnePlus qPCR system. Differential gene expression was determined by $\Delta \Delta C$ t method. Primers used are listed in Table 1 . 
Table 1

List of mouse primers

\begin{tabular}{|c|c|}
\hline Primer Name & Sequence \\
\hline \multirow[t]{2}{*}{ VSV-GFP } & F: GAGCGCACCATCTTCTTCAAG \\
\hline & R: TGTCGCCCTCGAACTTCAC \\
\hline \multirow[t]{2}{*}{ VSV-M } & F: TCGGTCTGAAGGGGAAAGGT \\
\hline & R: AGGTGTCCATCTCGTCAACTC \\
\hline \multirow[t]{2}{*}{ VSV-N } & F: GATAGTACCGGAGGATTGACGACTA \\
\hline & R: TCAAACCATCCGAGCCATTC \\
\hline \multirow[t]{2}{*}{ Ifna2 } & F: TGCTTTCCTCGTGATGCTGA \\
\hline & R: TCATCTGTGCCAGGACCTTC \\
\hline \multirow[t]{2}{*}{ Ifna4 } & F: GCCTTGACAGTCCTGGAAGA \\
\hline & R: TTGAGCTGCTGATGGAGGTC \\
\hline \multirow[t]{2}{*}{ Ifnb1 } & F: CAGCTCCAAGAAAGGACGAAC \\
\hline & R: GGCAGTGTAACTCTTCTGCAT \\
\hline \multirow[t]{2}{*}{ Ifnl2/3 } & F: AGCTGCAGGCCTTCAAAAAG \\
\hline & R: TGGGAGTGAATGTGGCTCAG \\
\hline \multirow[t]{2}{*}{ Oas } & F: GATGTCAAATCAGCCGTCAA \\
\hline & R: AGTGTGGTGCCTTTGCCTGA \\
\hline \multirow[t]{2}{*}{ Ifit2 } & F: AGTACAACGAGTAAGGAGTCACT \\
\hline & R: AGGCCAGTATGTTGCACATGG \\
\hline \multirow[t]{2}{*}{ Ifit3 } & F: GGGAAACTACGCCTGGATCTACT \\
\hline & R: CATGCTGTAAGGATTCGCAAAC \\
\hline \multirow[t]{2}{*}{116} & F: ATGATGGATGCTACCAAACTGGA \\
\hline & R: CTGAAGGACTCTGGCTTTGTCT \\
\hline \multirow[t]{2}{*}{ Cxcl10 } & F: ATCATCCCTGCGAGCCTATCCT \\
\hline & R: GACCTTTTTTGGCTAAACGCTTTC \\
\hline \multirow[t]{2}{*}{ Rela } & F: CTGCCGAGTAAACCGGAACT \\
\hline & R: GCCTGGTCCCGTGAAATACA \\
\hline
\end{tabular}




\section{Primer Name Sequence \\ Gapdh F: TGCACCACCAACTGCTTAG \\ Quantification of Apoptosis in the OE}

Coronal sections from rostral, middle and caudal regions of the OE were immunostaining for activated Caspase-3 (1:200, Cell Signaling) to identify apoptotic cells. OE areas of the septum and two turbinate regions of each section were selected based on the integrity of the tissue by DAPI staining without selecting activated Caspase-3 staining pattern. For each animal, twelve regions of each rostro-caudal area and a total of $3.6 \mathrm{~mm}$ in length throughout OE were confocal imaged. The number of activated Caspase-3 positive cells in the OE were counted and the number of cells per $\mathrm{mm}$ OE length was then calculated. Two animals of each time point, control, $3 \mathrm{hr}, 6 \mathrm{hr}, 12 \mathrm{hr}, 24 \mathrm{hr}$ and $48 \mathrm{hrPI}$ were analyzed.

\section{Results}

\section{VSVs infect olfactory sensory neurons}

To evaluate whether VSV gains access to the brain via the olfactory nerve by infecting OSNs, VSV12'GFP was placed at the nostrils of mice and inhaled into the nasal cavity. Temporal and cell-type specific viral transduction were examined by viral GFP expression. No GFP expression was observed in the OE at $6 \mathrm{hrs}$ post viral instillation (6 hrPI) (Fig. 1A). Scattered GFP positive cells were first observed at $12 \mathrm{hrPI}$

(Fig. 1B). All GFP positive cells observed at 12 hrPI have the morphology of mature OSNs (Fig. 1B). By 24 hrPI, GFP positive cells are widely distributed within the OE (Fig. 1C). In addition to OSNs, viral GFP expression is also observed in sustentacular cells and basal cells. The OE tissue shows degenerative changes including a decrease in the OE thickness at $48 \mathrm{hrPI}$ with viral GFP expression still evident (Fig. 1D). Viral GFP was observed in the olfactory nerve bundles within the lamina propria at $24 \mathrm{hrPI}$ (Fig. 1C). The VSV-GFP positive olfactory nerve continues into the olfactory nerve layer and glomerular layer of the OB (Fig. 1E-F). Increased GFP expression was observed in the olfactory nerve layer and glomerular layers of the OB at $48 \mathrm{hrPI}$. The GFP signal also co-localizes with OMP immunoreactivity labeling the olfactory axons and their terminal arbors within the glomeruli of the OB (Fig. 1G-H). No VSV 12 'GFP positive OB neurons were observed at either 24 or $48 \mathrm{hrPI}$ [13].

To determine the levels of viral replication in the $\mathrm{OM}$ and OB, viral GFP transcript levels were measured by qRT-PCR and compared at $3 \mathrm{hr}, 6 \mathrm{hr}, 12 \mathrm{hr}, 24 \mathrm{hr}$ and $48 \mathrm{hrPI}$. Viral GFP transcripts were identified at $3 \mathrm{hrPI}$, the earliest time point examined. GFP transcript levels continued to increase in the OM from $6 \mathrm{hrPI}$ to 48 hrPI (Fig. 1l, relative Log10 fold change (LogFC): 3 hrPI 2.34 $\pm 0.22 ; 6$ hrPI 2.75 $\pm 0.22 ; 12$ hrPI 4.67 \pm 0.09 ; $24 \mathrm{hrPI} 6.87 \pm 0.19 ; 48 \mathrm{hrPI} 7.4 \pm 0.007, \mathrm{p}<0.05)$. In the $\mathrm{OB}$, viral gene transcripts were not detected at 12 hrPI (Fig. 1J, LogFC:12 hrPI - 1.44 \pm 0.58 ). Compared to the PBS control, VSV-GFP transcript levels were 
significantly increased at $24 \mathrm{hrPl}$ and $48 \mathrm{hrPI}$ (Fig. 1J, LogFC: $24 \mathrm{hrPl} 4.26 \pm 0.15 ; 48 \mathrm{hrPI} 5.4 \pm 0.087, \mathrm{p}<$ 0.05).

During the acute phase of viral infection, within $48 \mathrm{hrPl}$, while viral replication is active in OSNs, the rates of apoptosis were investigated. Activated caspase 3 immunohistochemistry was performed on Control and VSV infected OE (Fig. 2). Increased numbers of apoptotic cells were observed compared to the wildtype control in $3 \mathrm{hr}, 6 \mathrm{hr}, 12 \mathrm{hr}, 24 \mathrm{hr}$ and $48 \mathrm{hrPI}$ (Fig. 2B, Cells/mm: wildtype 14.2 $\pm 1.73 \mathrm{hrPI} 90.6 \pm 2.7$; $6 \mathrm{hrPI} 58.3 \pm 4.7 ; 12 \mathrm{hrPI} 25.5 \pm 1.2 ; 24 \mathrm{hrPI} 35.8 \pm 10.8 ; 48 \mathrm{hrPI} 100 \pm 2.4, \mathrm{p}<0.05)$. Interestingly, increases of apoptosis occurred rapidly at $3 \mathrm{hrPI}$ and subsequently subsided before increasing again at $48 \mathrm{hrPI}$ when $\mathrm{OE}$ has undergone pathogenic changes.

\section{Acute changes of transcription profiles in the olfactory mucosa}

To better understand innate immune responses in the OM during acute phase of VSV exposure, we conducted RNA-seq analysis to systematically examine gene expression regulation within the first 48 $\mathrm{hrPI}$. Biological triplicates of OM were collected at 3hr, $6 \mathrm{hr}, 9 \mathrm{hr}, 24 \mathrm{hr}$ and $48 \mathrm{hrPI}$ after VSV or PBS nasal instillation. No significant gene expression changes between VSV and PBS control OM before 24hrPI. At $24 \mathrm{hrPl}, 1655$ transcripts showed differential expression greater than 2.5 folds in VSV samples compared to PBS (Fig. $3 \mathrm{~A}$, adjP < 0.05). The number of upregulated genes was higher than the number of downregulated genes (upregulated genes $=1230$ genes; downregulated genes $=425$ genes, adjP $<0.05$ ) . Amongst the genes showing robust differential expression are cytokines and chemokines (Fig. 3B-C). Gene ontology enrichment analysis was performed. GO terms related to antiviral responses were prominently recognized (Fig. 3D). The expression of selected transcripts was validated by qRT-PCR. Upregulation of $/ 16, C x C / 10$ and Rela at $24 \mathrm{hr}$ PI were validated (Fig. 3E-G). Though it did not show significant upregulation at $3 \mathrm{hrPI}$ by RNA-seq analysis, significant upregulation of $/ 16$, was detected by qRT-PCR $(5.29 \pm 0.29, p<0.05$, biological replicates $n=6)($ Fig. 3E).

\section{Upregulation of type I and III interferon transcript levels}

Gene ontology analysis identified a significant change in cellular response to interferon-beta at $24 \mathrm{hrPI}$ (Fig. 3D). In the mouse genome, there are 14 Ifn a isoforms, 1 If $\beta \beta$ isoform (type I) and 2 Ifn $\lambda$ isoforms (type III). Neither type I nor type III Ifn expression was detected in PBS treated OM. Exposure to VSV induced an upregulation of Ifn a2, $a 4, a 16, \beta 1, \lambda 2$ and $\lambda 3$ at $24 \mathrm{hrPl}$ and $48 \mathrm{hrPI}$ in the OM compared to PBS controls. Changes in transcription of Ifna2, Ifna4, Ifn $\beta 1$ and Ifn $\lambda 2 / 3$ at $12 \mathrm{hr}, 24 \mathrm{hr}$ and $48 \mathrm{hrPI}$ were validated by qRT-PCR (Fig. 4A-D, $p<0.05$ ). Type I and type III IFN receptors are expressed in control OM. Compared to PBS control OM, type I Ifn receptor subunit (Ifnar1) and type III Ifn lambda receptor subunit (Ifn/r7) levels were not changed following VSV exposure at $24 \mathrm{hrPI}$ as determined by RNA-seq analysis (Fig. 4E, adjP < 0.05). 
To determine cell type specific expression of Ifn receptors, immunohistochemistry was performed to detect protein expression of IFNAR1 and IFNLR1. Mature OSNs were identified by olfactory marker protein (OMP) immunostaining. IFNAR1 expression was detected throughout the depth of the OE and appears to be localized in the majority of the OM cell types, including OSNs (Fig. 4F). IFNLR1 expression was less ubiquitous in the OE. Immunoreactivity of IFNLR1 in the sustentacular cell body layer at the apical surface of the OE was not evident. However, IFNLR1 expression was detected in OMP positive OSNs throughout the OE (Fig. 4G). IFNLR1 expression was also observed in the olfactory nerve bundles, labeled by OMP immunoreactivity, in the lamina propria. Therefore, IFNLR1 is specifically expressed in mature OSNs.

\section{Activation of interferon signaling in the olfactory epithelium}

The activation of type I and type III Ifn receptors results in phosphorylation of STAT1 (PSTAT1) and STAT2 (pSTAT2), which subsequently regulate Ifn stimulated genes (ISGs) expressing to perform antiviral functions $[27,28]$. To investigate whether exposure to VSV activates Ifn signaling in the OM, we first examined pSTAT 1 and pSTAT2 levels by western blotting. PSTAT1 and PSTAT2 are not detected in PBS control OM while they are clearly present in VSV exposed OM at 24 hrPI (Fig. 5A-B). pSTAT1 and pSTAT2 levels were quantified and normalized against a-tubulin loading control. Comparisons of VSV to PBS in biological triplicate OMs show significant changes in pSTAT1 and pSTAT2 at $24 \mathrm{hrPI}$ (pSTAT1 PBS vs VSV: $0.063 \pm 0.018$ vs $0.30 \pm 0.048$; pSTAT2 PBS vs VSV: $0.62 \pm 0.4$ vs $2.5 \pm 1.05, p<0.05$ ).

To investigate the cell type specific STAT activation, immunocytochemistry was performed to detect pSTAT1 expression in the OE. PSTAT1 was detected in majority of cell types, including OSNs, at low levels in the PBS control. At 24 hrPI VSV, pSTAT1 appears in the nuclei of majority of cell types and robustly in sustentacular cells (Fig. 5C).

Expression levels of ISGs were evaluated in VSV exposed OM and compared with PBS controls by qRTPCR (Fig. 5D-F). Upregulation of Oas1, Ifit2 and Ifit3 transcript levels were first detected at $12 \mathrm{hrPI}$ (Fold: 12 hrPl: Oas1 2.14 \pm 0.075 , Ifit2 1.83 \pm 0.06 , Ifit3 6.5 $\pm 0.05 ; 24$ hrPI: Oas1 29.8 \pm 0.13 , Ifit2 16.9 \pm 0.11 , Ifit3 $93.1 \pm 0.11 ; 48$ hrPl: Oas1 $28.49 \pm 0.13$, Ifit2 23.95 \pm 0.14 , Ifit3 $86.6 \pm 0.13 p<0.05$ ). Increased levels of upregulation of ISGs were observed at $24 \mathrm{hr}$ and $48 \mathrm{hrPI}$ compared to that of $12 \mathrm{hrPI}$.

\section{Interferon signaling is required for suppressing VSV replication in the olfactory mucosa}

To determine whether Ifn signaling is required for performing antiviral functions in the OM, we examined VSV viral load in Ifnar1 and IfnIr 1 knockout mice and compared it to Ifnar1 and Ifn/r1 wildtype OM. Relative expression levels of the three viral genes VSV-GFP, VSV-M and VSV-N were measured at $24 \mathrm{hrPI}$. In Ifnar1 knockout OM, all three viral genes examined are slightly increased relative to the wildtype, but the change is not significant. (Fig. 6A, relative fold Ifnar ${ }^{-/-}$: VSV-GFP: $1.43 \pm 0.042$; VSV-M: $1.48 \pm 0.03$; VSV$\mathrm{N}: 1.54 \pm 0.052, p>0.05)$. 
Similarly in Ifn/r knockout OM, slight non-significant increases were observed in VSV viral gene expression compared to wildtype (Fig. 6B, relative fold Ifnlr ${ }^{-/-}$: VSV-GFP: $1.57 \pm 0.09$; VSV-M: $1.27 \pm 0.12$; VSV-N: $1.4 \pm 0.07, \mathrm{p}>0.05)$. However, in OM from Ifnar1 ${ }^{-/-} / I f n / r 1^{-/-}$double knockout mice, significant increases in viral genes expression were detected by qRT-PCR (Fig. 6C, relative fold to PBS: VSV-GFP: $2.4 \pm 0.51$; VSV-M: $3.5 \pm 0.47$; VSV-N: $3.43 \pm 0.41, \mathrm{p}<0.05)$. Furthermore, knocking out Stat1 which disrupts both type I and type III Ifn signaling, also results in a significant increase in viral gene expression (Fig. 6D, relative fold: VSV-GFP: 2.87; VSV-M: 5.71; VSV-N: 3.97, p<0.05). These results indicate that both type I and type III Ifn signaling are required for suppressing viral replication in the OM.

Furthermore, we investigated whether IFNs are sufficient in reducing viral load in the OM. Exogenous IFN $\beta 1$, IFN $\lambda 2$, or PBS was provided via nasal instillation to wildtype mice 1 hour before VSV exposure. Viral transcript levels were examined at $24 \mathrm{hr}$ post viral instillation and compared between PBS and IFN groups in biological triplicates. It was observed that the administration of IFN 1 1 significantly decreases the relative number of viral transcripts of all three viral genes in the OM (Fig. 7A, relative fold to PBS: VSVGFP: $0.18 \pm 0.26$; VSV-M: $0.21 \pm 0.27$; VSV-N: $0.19 \pm 0.26, p<0.05$ ). Consistently, viral transcript levels significantly decreased in the $\mathrm{OB}$ at $24 \mathrm{hrPI}$ as well when primed with IFNB1 (Fig. 7B, relative fold to PBS: VSV-GFP: $0.26 \pm 0.27$; VSV-M: $0.27 \pm 0.27$; VSV-N: $0.26 \pm 0.27, \mathrm{p}<0.05)$. When comparing priming with exogenous IFN $\lambda 2$ to PBS before VSV exposure, significant decreases of viral transcripts were observed at $24 \mathrm{hrPI}$ for all three viral genes in the OM (Fig. 7C, relative fold to PBS: VSV-GFP: $0.17 \pm 0.07$; VSV-M: $0.12 \pm 0.06$; VSV-N: $0.17 \pm 0.08, p<0.05)$. Consistently, viral transcript levels were also significantly decreased $24 \mathrm{hrPI}$ in the OB following IFN $\lambda 2$ priming of the OE (Fig. 7D, relative fold to PBS: VSV-GFP: $0.2 \pm 0.44$; VSV-M: $0.29 \pm 0.28$; VSV-N: $0.65 \pm 0.25 p<0.05$ ). These results indicate that type I and type III IFNs are both sufficient to suppress viral replication in the OM. VSV-GFP expression was examined on OE sections. Consistent with qRT-PCR, VSV-GFP was diminished in IFN 11 primed OE. GFP positive cells were scarcely scattered in the basal cell layer of the OE in IFN 22 treated animals (Fig. 7E-G). This data may reflect the expression differences between type I and III receptors.

\section{Discussion}

Despite its vulnerability to pathogen exposure, the mammalian olfactory mucosa's innate immune responses to viral infection have not been characterized in detail. In this study, we report that VSV infects the majority of cell types in the $\mathrm{OE}$. Acute transcriptional responses are observed as early as 3hrs post VSV nasal infection. Following VSV exposure, both type I and type III IFNs are upregulated. Activation of their signaling pathways are detected within the OM. Genetic analyses indicate that IFN signaling is required to control VSV viral load in the OM.

The glycoprotein G of VSV is widely used to pseudotype other viruses for gene transfer. The receptor for viral entry of VSV, Low density lipoprotein receptor $(L d / r)$, is expressed in the olfactory mucosa. It is expected that VSVs are able to infect cells in the OE. Nasal instillation of VSV results in viral entry into the $\mathrm{OB}$, likely through the olfactory nerve [13]. Consistent with previous studies, VSV infection and viral replication in OSNs were observed and are widespread at $24 \mathrm{hrPI}$ [10]. The attenuated VSV strain, 
VSV12'GFP, used in this study is reported to replicate slower than the wildtype Indiana strain. Nonetheless, we detected GFP expression as early as $12 \mathrm{hrPI}$ in the OSNs, suggesting that the virus can efficiently enter OSNs and take over cellular machinery of the OM to replicate. Viral GFP expression in sustentacular cells were not detected until $24 \mathrm{hrPl}$. This may reflect the capability of Sus cells to mount a rapid and robust antiviral response. At $24 \mathrm{hrPl}$, viral GFP can be detected in olfactory nerve bundles within the $\mathrm{OM}$ as well as in the olfactory nerve layer and in the terminals of the olfactory nerve within the glomeruli of the $\mathrm{OB}$. These observations are consistent with studies suggesting that instead of packaging in the cell body, VSVs transport their viral proteins to the nerve terminals and assemble into virions locally for shedding [29]. For the time points analyzed up to $48 \mathrm{hrPl}$, we did not detect any viral GFP in OB cells. Further experiments are needed to determine whether VSV12'GFP spread is effectively blocked in the OB [13].

Limiting viral spread in the OE is particularly critical due to its direct connection with the CNS. It has been established that viral exposure triggers acute innate immune responses including proinflammatory cytokines and chemokines in many tissue types [30,31]. To systematically evaluate the dynamics of transcriptional responses, we performed RNA-seq analysis of the whole OM harvested at different time points post-viral exposure. It is evident that the majority of cytokines and chemokines are either not expressed or expressed at very low levels at resting state. Comparing to vehicle controls, with three biological replicates, we did not detect significant transcriptional changes before $24 \mathrm{hrPl}$. When selected cytokines were examined by qRT-PCR, we did detect significant increases of $/ / 6$ expression at $3 \mathrm{hrPI}$. //6 transcripts were upregulated at $3 \mathrm{hrPI}$ in RNA-seq dataset but it did not reach statistical significance ( $\operatorname{LogFC}=1.8 \mathrm{VSV} / \mathrm{PBS}$, adjP $=0.76$ ). It is possible that transcriptional changes happened in a small subset of cells and therefore the differential expression was not detectable at significant levels when analyzing global changes. Further study is needed to dissect the cell type specific contribution to these gene expression changes.

IFNs are antiviral cytokines that are critical in cellular defense mechanisms against viral infections. Ifn signaling is particularly important in neurons as they are postmitotic and not typically replaced following damage. OSNs are a special type of neurons, which can be replaced throughout animals' lifetime. Whether OSNs utilized the same strategy to suppress viral replication and protect from cell death is not known [7, 32]. Ifng signaling is shown to be critical for neuronal protection in the CNS [32]. In this study, Ifng expression is not detected in either control or VSV stimulated OE. Among the 13 type I Ifn isoforms,

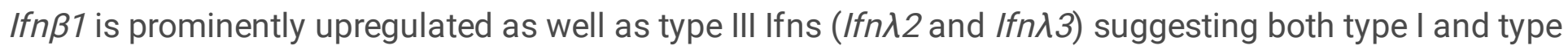
III Ifns are involved in the VSV-induced responses. Consistent with many tissue types, type I Ifn receptor, Ifnar1, is ubiquitously expressed in the OE. In contrary, type III Ifns receptor, IfnI 1 , is specifically expressed in mature OSNs. The presence of both type I and type III Ifns receptors suggest that OSNs are equipped with antiviral protection from both If $n$ types. With the upregulation of Ifn $\beta 1$ and Ifn $\lambda 2 / 3$, we expected that loss of function of either IFNAR1 or IFNLR1 would result in reduced antiviral activity. However, neither IFNAR1 nor IFNLR1 knockout, by itself, resulted in increased viral copy number in the OE when compared to the vehicle control. Only in Ifnar $1^{-/-} /$IfnIr $1^{-/-}$double knockout mice, did VSV load increase in the OE 
following VSV challenge. These findings suggest that Ifn signaling indeed inhibits VSV replication in the OE. Lack of evident antiviral effect in the single IFNAR1 or IFNLR1 receptor knockout mice could be the result of Ifn signaling compensation between the two different types. It is also possible that type I and type III Ifn levels are relatively low in the OM and therefore are not able to exert consistent detectable differences by taking away one IFN signaling pathway. Both type I and type III IFN receptor activation results in the phosphorylation of STAT1 which subsequently activates transcription [33,34]. Consistent with the receptor double knockout results, we also observe decreased viral replication inhibition in the Stat $^{-/-}$OE. These observations indicate that an effective antiviral response utilizes both type I and type III IFN signaling pathways.

IFN $\lambda$ is produced in many tissues in response to viral infection [35-37]. Though IFN $\lambda$ is believed to regulate the same set of genes as type I IFNs, IFNLR1 expression is limited to certain cell types and therefore functions in a tissue specific manner [38]. The expression of type I and type III receptors is not upregulated after viral exposure. Activation of IFN signaling is controlled by the upregulation of IFN isoforms. We noticed that PSTAT1 was localized in OSNs in control OE. This may indicate that OSNs maintains a heightened antiviral state. Under VSV exposure, however, pSTAT1 was more prominent in the nuclei of Sus cells suggesting rapid protective responses by Sus cells. The impact of IFN antiviral function is evident when exogenous IFN $\beta 1$ or IFN $\lambda 2$ were provide prior to VSV infection. The robust effect of exogenous IFNs on suppressing viral replication in the OE indicated that the interferon signaling pathway is in place and can be utilized to protect the $\mathrm{OE}$. It is still unclear which cell types in the $\mathrm{OE}$ produces IFNs upon viral insult and whether IFN signaling protects OSNs from undergoing apoptosis.

\section{Conclusion}

$\mathrm{OE}$ is a critical barrier, which is in constant contact with microbe filled environment as well as connected with the brain directly via the olfactory nerve. We systematically characterized the rapid transcriptional responses in the olfactory mucosa upon VSV exposure and shown that OE possesses innate ability to suppress viral infection. Type I and type III IFNs actively participate in the OE's antiviral functions. Nasal IFN application effectively blocks viral replication in the OE suggesting therapeutic potential against viral insult.

\section{Abbreviations}




\begin{tabular}{|ll|}
\hline OM & Olfactory Mucosa \\
\hline OB & Olfactory Bulb \\
\hline OE & Olfactory Epithelium \\
\hline Sus & Sustentacular \\
\hline OSN & Olfactory Sensory Neurons \\
\hline VSV & Vesicular Stomatitis Virus \\
\hline PBS & Phosphate Buffered Saline \\
\hline CNS & Central Nervous System \\
\hline hr & Hour \\
\hline PI & Post Instillation \\
\hline IFN & Interferon \\
\hline ISG & Interferon Stimulated Genes \\
\hline
\end{tabular}

\section{Declarations}

\section{o Competing interests}

The authors declare that they have no competing interests.

\section{o Consent for publication}

Not applicable

\section{o Funding}

This study is supported by NIH DC016183 to QG

\section{o Authors' contributions}

$A Z, A D W, Q G$ designed the experiments, $A Z, A D W, W Y, S W, A T$ and $Q G$ performed the experiments and analyzed the data, AZ, AW, QG prepared the manuscript. All authors read and approved the final paper.

\section{o Acknowledgement}




\section{o Ethical Approval and Consent to participate}

Not applicable

\section{References}

1. Farbman Al. Cell Biology of Olfaction. Cambridge University Press; 1992.

2. $10.3389 /$ fnana.2014.00063/full

Barrios AW, Núñez G, Sánchez Quinteiro P, Salazar I. Anatomy, histochemistry, and immunohistochemistry of the olfactory subsystems in mice. Front Neuroanat [Internet]. 2014 [cited 2019 Dec 12];8. Available from: https://www.frontiersin.org/articles/10.3389/fnana.2014.00063/full.

3. Boekhoff I, Tareilus E, Strotmann J, Breer H. Rapid activation of alternative second messenger pathways in olfactory cilia from rats by different odorants. The EMBO Journal. 1990;9:2453-8.

4. Challis RC, Tian $\mathrm{H}$, Wang J, He J, Jiang J, Chen $\mathrm{X}$, et al. An Olfactory Cilia Pattern in the Mammalian Nose Ensures High Sensitivity to Odors. Curr Biol. 2015;25:2503-12.

5. Menco BP, Cunningham AM, Qasba P, Levy N, Reed RR. Putative odour receptors localize in cilia of olfactory receptor cells in rat and mouse: a freeze-substitution ultrastructural study. J Neurocytol. 1997;26:691-706.

6. Milho R, Frederico B, Efstathiou S, Stevenson PG. A Heparan-Dependent Herpesvirus Targets the Olfactory Neuroepithelium for Host Entry. PLOS Pathogens. 2012;8:e1002986.

7. Schwob JE, Saha S, Youngentob SL, Jubelt B. Intranasal Inoculation with the Olfactory Bulb Line Variant of Mouse Hepatitis Virus Causes Extensive Destruction of the Olfactory Bulb and Accelerated Turnover of Neurons in the Olfactory Epithelium of Mice. Chem Senses. 2001;26:937-52.

8. Bryche B, Frétaud M, Deliot AS-A, Galloux M, Sedano L, Langevin C, et al. Respiratory syncytial virus tropism for olfactory sensory neurons in mice. Journal of Neurochemistry. n/a:e14936.

9. Barnett EM, Perlman S. The olfactory nerve and not the trigeminal nerve is the major site of CNS entry for mouse hepatitis virus, strain JHM. Virology. 1993;194:185-91.

10. Reiss CS, Plakhov IV, Komatsu T. Viral Replication in Olfactory Receptor Neurons and Entry into the Olfactory Bulb and Braina. Ann N Y Acad Sci. 1998;855:751-61.

11. Ozdener MH, Donadoni M, Cicalese S, Spielman Al, Garcia-Blanco A, Gordon J, et al. Zika virus infection in chemosensory cells. J Neurovirol. 2020.

12. Barthold SW. Olfactory neural pathway in mouse hepatitis virus nasoencephalitis. Acta Neuropathol. 1988;76:502-6.

13. van den Pol AN, Ding S, Robek MD. Long-distance interferon signaling within the brain blocks virus spread. J Virol. 2014;88:3695-704. 
14. Detje CN, Meyer T, Schmidt H, Kreuz D, Rose JK, Bechmann I, et al. Local type I IFN receptor signaling protects against virus spread within the central nervous system. J Immunol. 2009;182:2297-304.

15. Detje CN, Lienenklaus S, Chhatbar C, Spanier J, Prajeeth CK, Soldner C, et al. Upon Intranasal Vesicular Stomatitis Virus Infection, Astrocytes in the Olfactory Bulb Are Important Interferon Beta Producers That Protect from Lethal Encephalitis. J Virol. 2014;89:2731-8.

16. Mori I. Transolfactory neuroinvasion by viruses threatens the human brain. Acta Virol. 2015;59:33849.

17. Miller KD, Schnell MJ, Rall GF. Keeping it in check: chronic viral infection and antiviral immunity in the brain. Nat Rev Neurosci. 2016;17:766-76.

18. Schwob JE, Jang W, Holbrook EH, Lin B, Herrick DB, Peterson JN, et al. Stem and Progenitor Cells of the Mammalian Olfactory Epithelium: Taking Poietic License. J Comp Neurol. 2017;525:1034-54.

19. Hasegawa-Ishii S, Shimada A, Imamura F. Lipopolysaccharide-initiated persistent rhinitis causes gliosis and synaptic loss in the olfactory bulb. Sci Rep [Internet]. 2017 [cited 2018 Sep 23];7. Available from: https://www.ncbi.nlm.nih.gov/pmc/articles/PMC5599676/.

20. Kanaya K, Kondo K, Suzukawa K, Sakamoto T, Kikuta S, Okada K, et al. Innate immune responses and neuroepithelial degeneration and regeneration in the mouse olfactory mucosa induced by intranasal administration of Poly(l:C). Cell Tissue Res. 2014;357:279-99.

21. Mori I, Goshima F, Imai Y, Kohsaka S, Sugiyama T, Yoshida T, et al. Olfactory receptor neurons prevent dissemination of neurovirulent influenza A virus into the brain by undergoing virus-induced apoptosis. J Gen Virol. 2002;83:2109-16.

22. Sepahi A, Kraus A, Casadei E, Johnston CA, Galindo-Villegas J, Kelly C, et al. Olfactory sensory neurons mediate ultrarapid antiviral immune responses in a TrkA-dependent manner. Proceedings of the National Academy of Sciences. 2019;116:12428-36.

23. Lawler C, Stevenson PG. Type I Interferon Signaling to Dendritic Cells Limits Murid Herpesvirus 4 Spread from the Olfactory Epithelium. J Virol. 2017;91.

24. Jacobs S, Zeippen C, Wavreil F, Gillet L, Michiels T. IFN- $\lambda$ Decreases Murid Herpesvirus-4 Infection of the Olfactory Epithelium but Fails to Prevent Virus Reactivation in the Vaginal Mucosa. Viruses. 2019;11.

25. Trottier MD, Lyles DS, Reiss CS. Peripheral, but not central nervous system, type I interferon expression in mice in response to intranasal vesicular stomatitis virus infection. J Neurovirol. 2007;13:433-45.

26. van den Pol AN, Davis JN. Highly attenuated recombinant vesicular stomatitis virus VSV-12'GFP displays immunogenic and oncolytic activity. J Virol. 2013;87:1019-34.

27. Durbin RK, Kotenko SV, Durbin JE. Interferon Induction and Function at the Mucosal Surface. Immunol Rev. 2013;255:25-39.

28. Schneider WM, Chevillotte MD, Rice CM. Interferon-stimulated genes: a complex web of host defenses. Annu Rev Immunol. 2014;32:513-45. 
29. Taylor MP, Enquist LW. Axonal spread of neuroinvasive viral infections. Trends Microbiol. 2015;23:283-8.

30. Mesev EV, LeDesma RA, Ploss A. Decoding type I and III interferon signalling during viral infection. Nat Microbiol. 2019;4:914-24.

31. Melchjorsen J. Learning from the Messengers: Innate Sensing of Viruses and Cytokine Regulation of Immunity - Clues for Treatments and Vaccines. Viruses. 2013;5:470-527.

32. D'Agostino PM, Yang J, Reiss CS. DISTINCT MECHANISMS OF INHIBITION, OF VSV REPLICATION IN NEURONS MEDIATED BY TYPE I AND TYPE II IFN. Virus Rev Res. 2009;14:20-9.

33. Beadling C, Guschin D, Witthuhn BA, Ziemiecki A, Ihle JN, Kerr IM, et al. Activation of JAK kinases and STAT proteins by interleukin-2 and interferon alpha, but not the $T$ cell antigen receptor, in human $T$ lymphocytes. EMBO J. 1994;13:5605-15.

34. Darnell JE, Kerr IM, Stark GR. Jak-STAT pathways and transcriptional activation in response to IFNs and other extracellular signaling proteins. Science. American Association for the Advancement of Science; 1994;264:1415-21.

35. Hillyer P, Mane VP, Schramm LM, Puig M, Verthelyi D, Chen A, et al. Expression profiles of human interferon-alpha and interferon-lambda subtypes are ligand- and cell-dependent. Immunol Cell Biol. 2012;90:774-83.

36. Baldridge MT, Lee S, Brown JJ, McAllister N, Urbanek K, Dermody TS, et al. Expression of Ifnlr1 on Intestinal Epithelial Cells Is Critical to the Antiviral Effects of Interferon Lambda against Norovirus and Reovirus. J Virol. 2017;91.

37. Donnelly RP, Kotenko SV. Interferon-Lambda. A New Addition to an Old Family. J Interferon Cytokine Res. 2010;30:555-64.

38. Lazear HM, Nice TJ, Diamond MS. Interferon- $\lambda$ : Immune Functions at Barrier Surfaces and Beyond. Immunity. 2015;43:15-28.

\section{Figures}



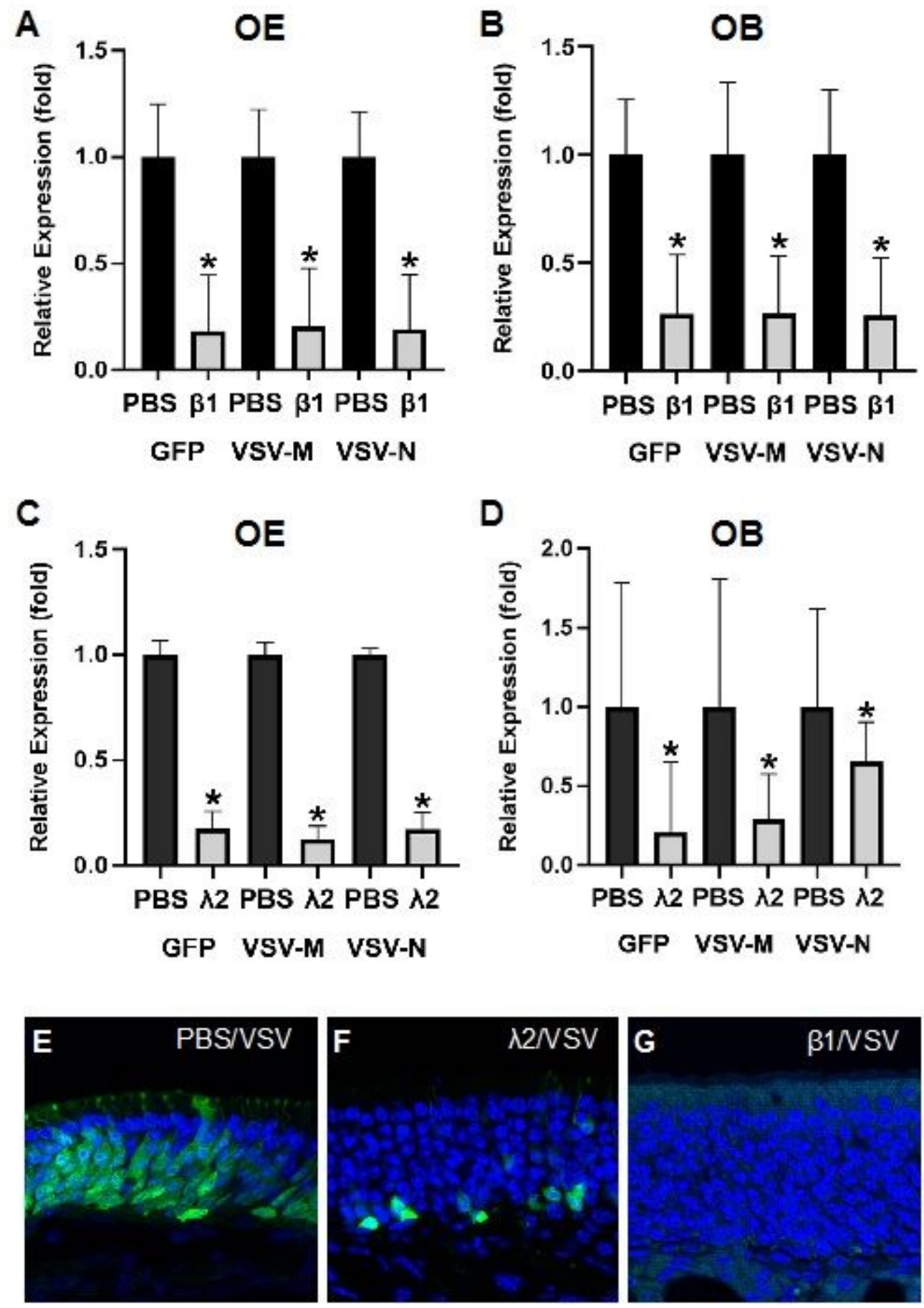

Figure 1

Type I and III interferons are sufficient to suppress viral load in the olfactory mucosa. Antiviral functions of type I and III interferons were examined by providing exogenous recombinant mouse interferon $\beta 1$ (A, $B, G)$ and interferon $\lambda 2(C, D, F)$. PBS were instilled as control. Interferon or PBS was provided an hour before VSV instillation. VSV-GFP, $M$ and $N$ gene expression were measured $24 \mathrm{hrPI}$ in the $\mathrm{OE}(\mathrm{A}, \mathrm{C})$ and $\mathrm{OB}$ $(B, D)$. VSV-GFP protein reduction was observed in the OE $24 \mathrm{hrPI}$ for exogenous IFN $\lambda 2$ (F) and IFN $\beta 1$ (G). $\triangle$ indicates $p<0.05$. 

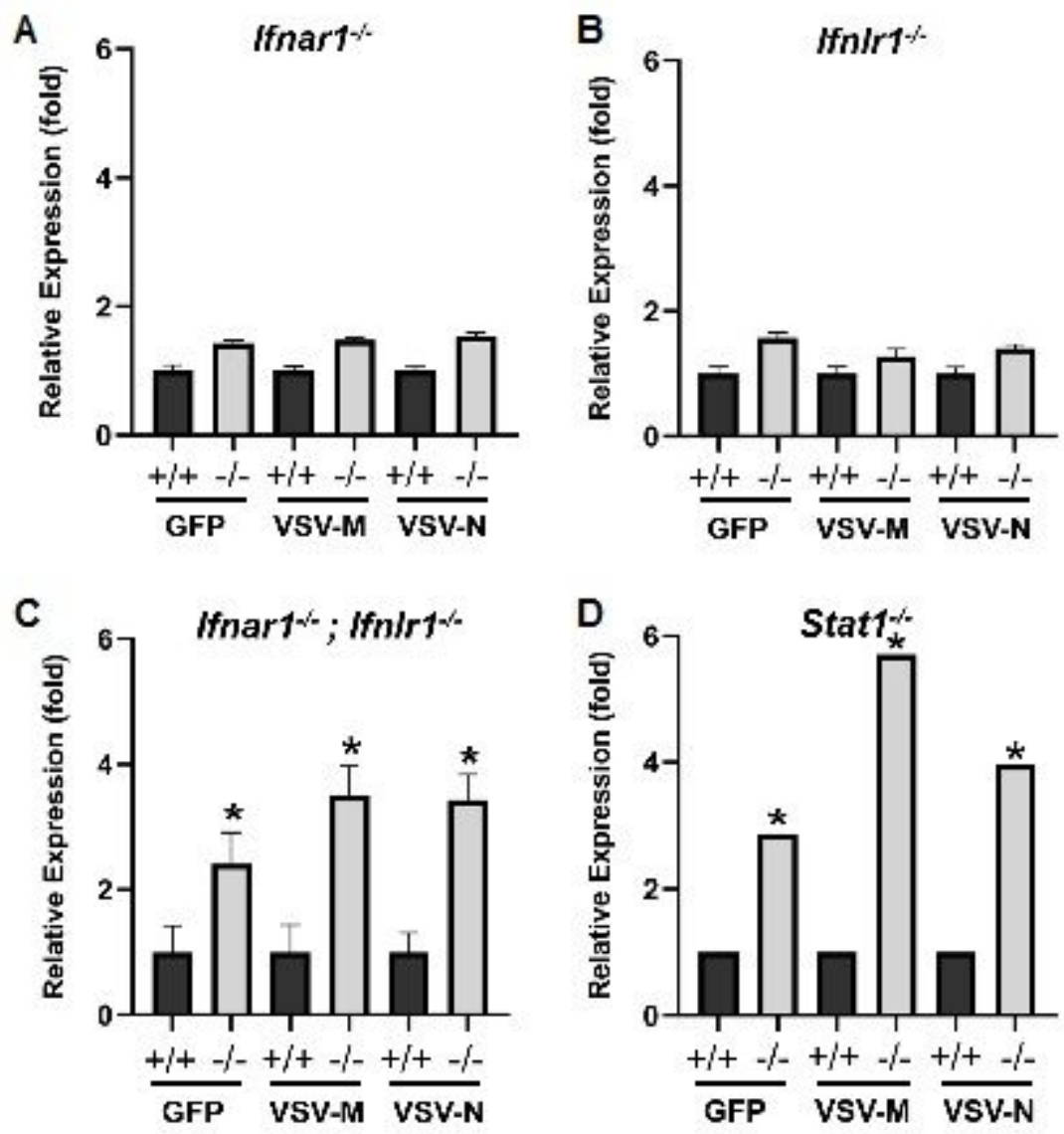

Figure 2

Interferon signaling is required for suppressing VSV replication in the olfactory mucosa The expression levels of the viral genes, VSV-GFP, VSV-M and VSV-N, in olfactory mucosae at $24 \mathrm{hrPI}$ are measured in Ifnar1-/- (A), IfnIr1-/- (B), Ifnar1-/-;fnIr1-/- (C) and Stat-/- (D) and compared to wildtype littermates. 
A

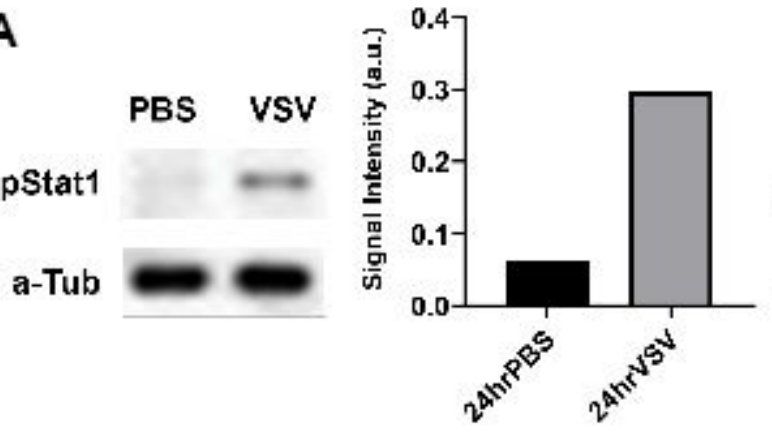

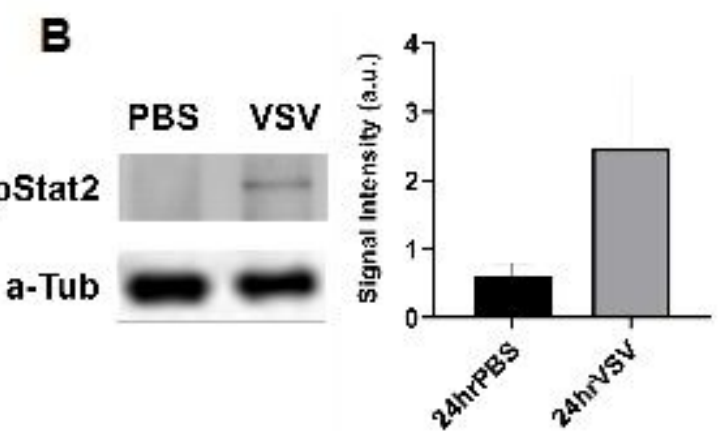

C 24hr PBS

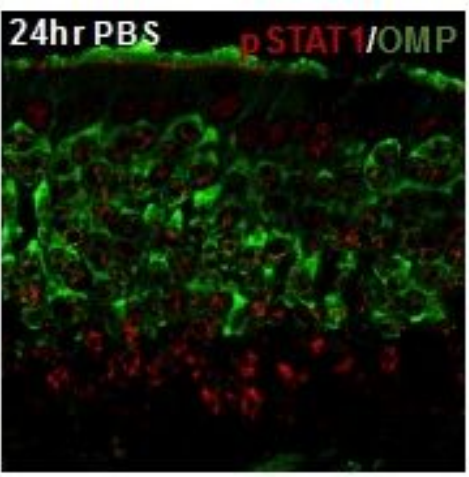

24hr VSV PSTAT IOMP

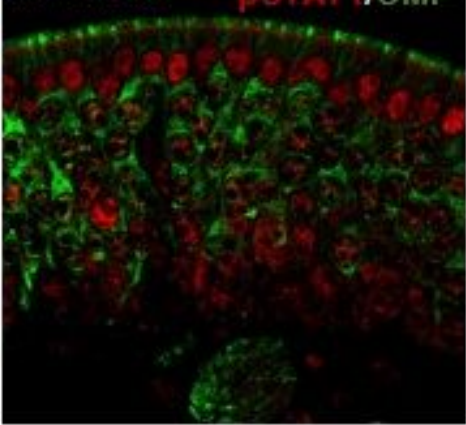

D

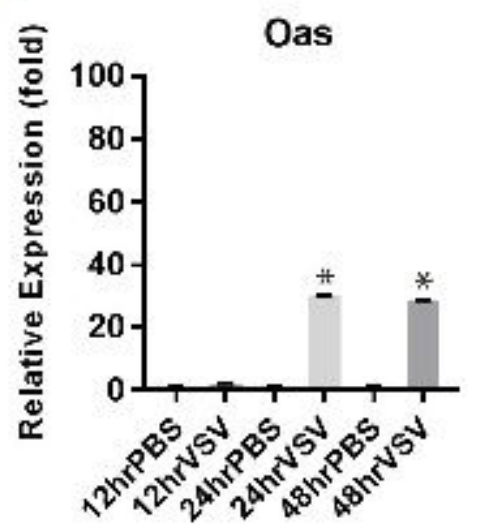

E

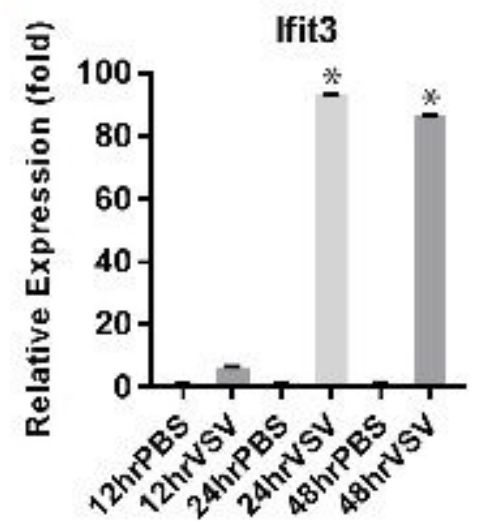

$\mathbf{F}$

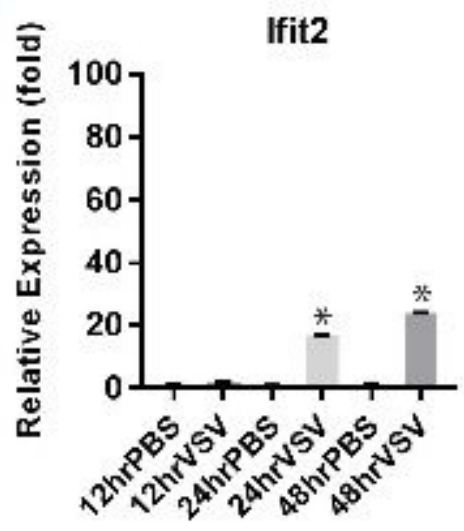

\section{Figure 3}

Activation of interferon signaling in the olfactory epithelium upon VSV exposure. pSTAT1 and pSTAT2 levels in the olfactory mucosa are examined by western blotting in $24 \mathrm{hrPI}$ and signals quantified against a-tubulin loading control (A, B). Immunohistochemistry of pSTAT1 in the $24 \mathrm{hrPI} \mathrm{OE} \mathrm{(C).} \mathrm{Relative}$ expression of interferon stimulated genes, Oas, Ifit2 and Ifit3 are determined by qRT-PCR (D-F). 
A

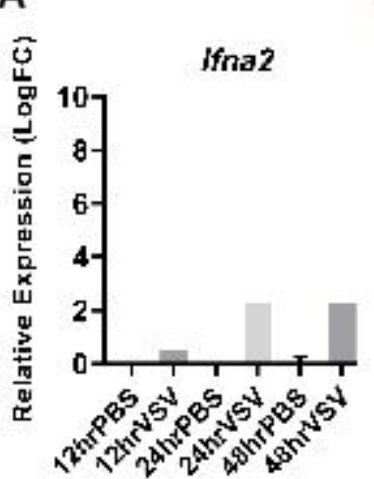

E

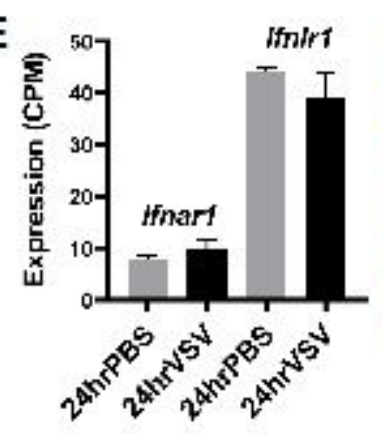

B

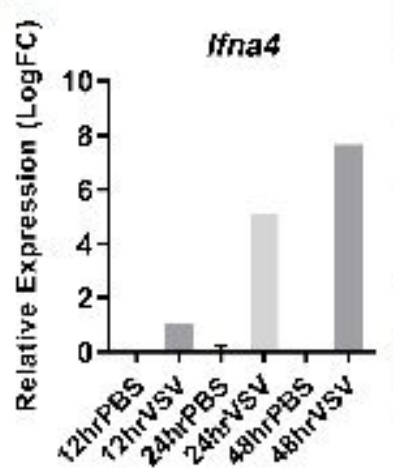

C

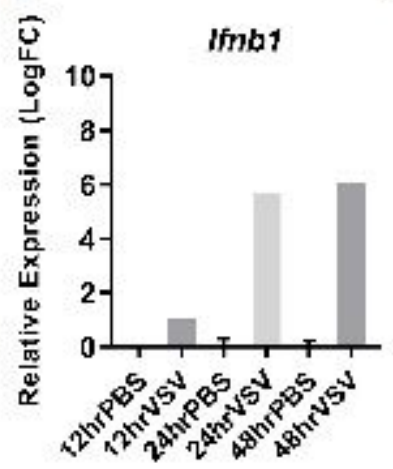

D

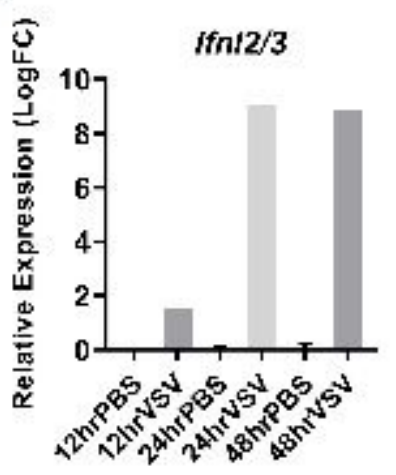

\section{Figure 4}
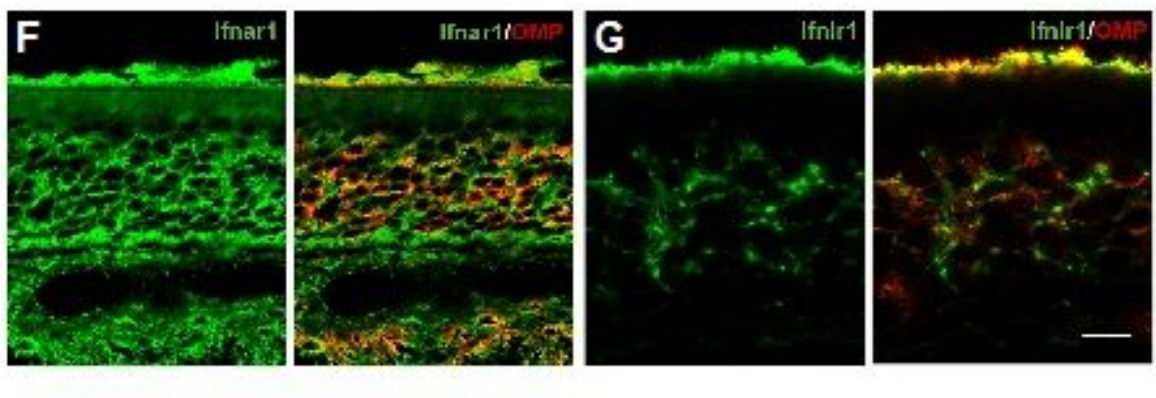

Upregulation of type I and III interferon transcript levels. Relative expression of Ifna2, Ifna4, Ifnb2 and Ifnl2/3 in the olfactory mucosa by qRT-PCR (A-D). Transcript expression of Ifnar 1 and Ifnlr1 in the olfactory mucosa at $24 \mathrm{hrPI}$. CPM, normalized counts per million. (E). Immunostaining of IFNAR1 (green in F) and IFNLR1 (green in G) with OMP (red in F and G) in OE. Bar = 15um 
A

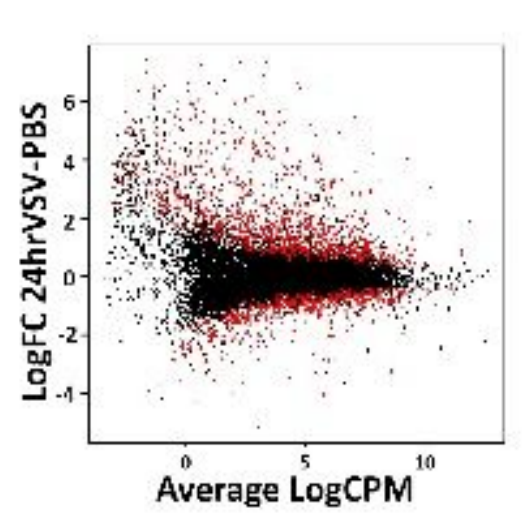

B Chemokines

$3 \mathrm{hr} \quad 6 \mathrm{hr} \quad 9 \mathrm{hr} \quad 24 \mathrm{hr} \quad 48 \mathrm{hr}$
C Cytokines

3hr 6hr $9 \mathrm{hr} 24 \mathrm{hr} 48 \mathrm{hr}$
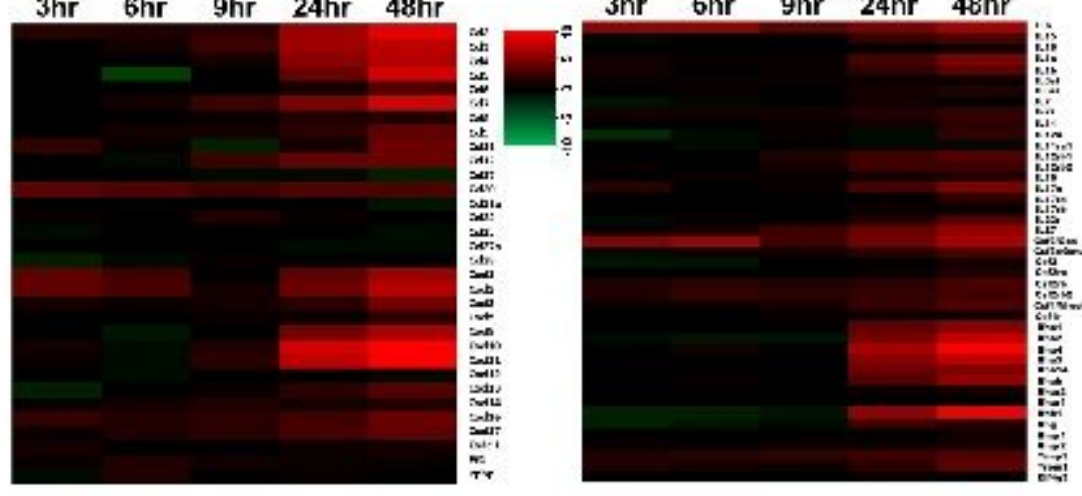

D

\begin{tabular}{|l|l|l|}
\hline GO.ID & Term & Raw p-value \\
\hline GO:0051607 & defense response to virus & $3.80 \mathrm{E}-15$ \\
\hline GO:0035458 & cellular response to interferon-beta & $9.00 \mathrm{E}-10$ \\
\hline GO:0045071 & hegative regulation of viral genome replication & $1.30 \mathrm{E}-09$ \\
\hline GO:0045087 & innate immune response & $7.50 \mathrm{E}-08$ \\
\hline
\end{tabular}

E

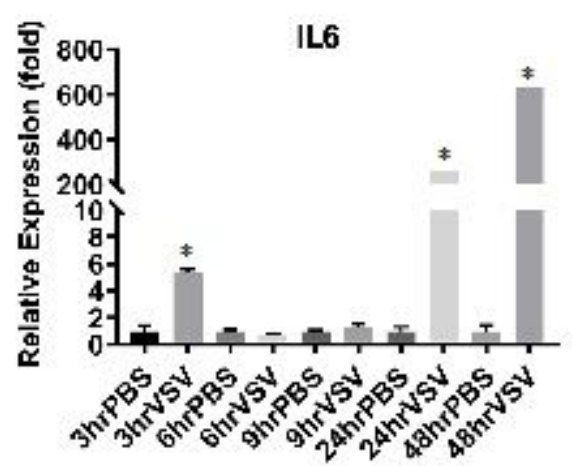

F

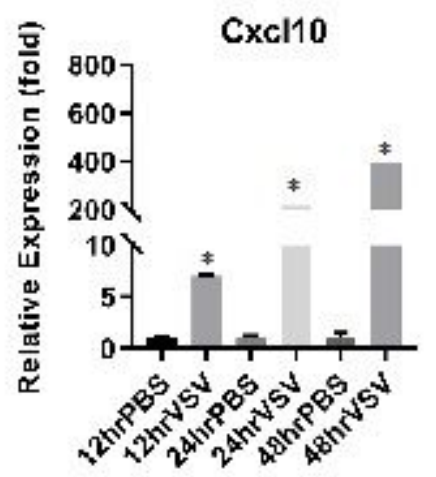

G

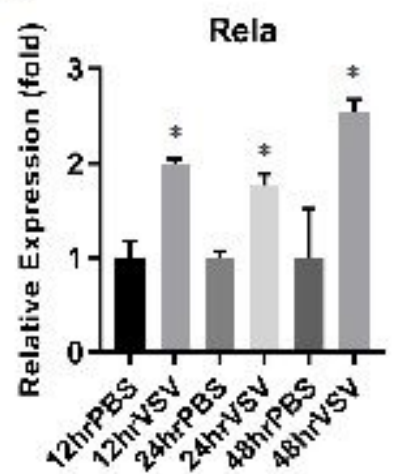

\section{Figure 5}

VSV exposure triggers acute changes of transcription profiles in the olfactory mucosa. Scatter plot comparing gene expression differences between VSV and PBS exposed olfactory mucosa at $24 \mathrm{hrPI}$ by RNA-seq (A) Red dots represent genes with adjP $<0.05$. Heatmap of chemokines and cytokine levels at $3 \mathrm{hr}, 6 \mathrm{hr}, 9 \mathrm{hr}, 24 \mathrm{hr}$ and $48 \mathrm{hrPI}(\mathrm{B}, \mathrm{C})$. Significant associations of gene ontology among differentially expressed transcripts between VSV and PBS control olfactory mucosa at $24 \mathrm{hrPI}$ (D). Upregulation of II6, Cxcl10 and Rela at 3hr, 6hr, $12 \mathrm{hr}, 24 \mathrm{hr}$ and $48 \mathrm{hrPI}$ by qRT-PCR. ${ }^{*} \mathrm{p}<0.05$ (E-G). 
A

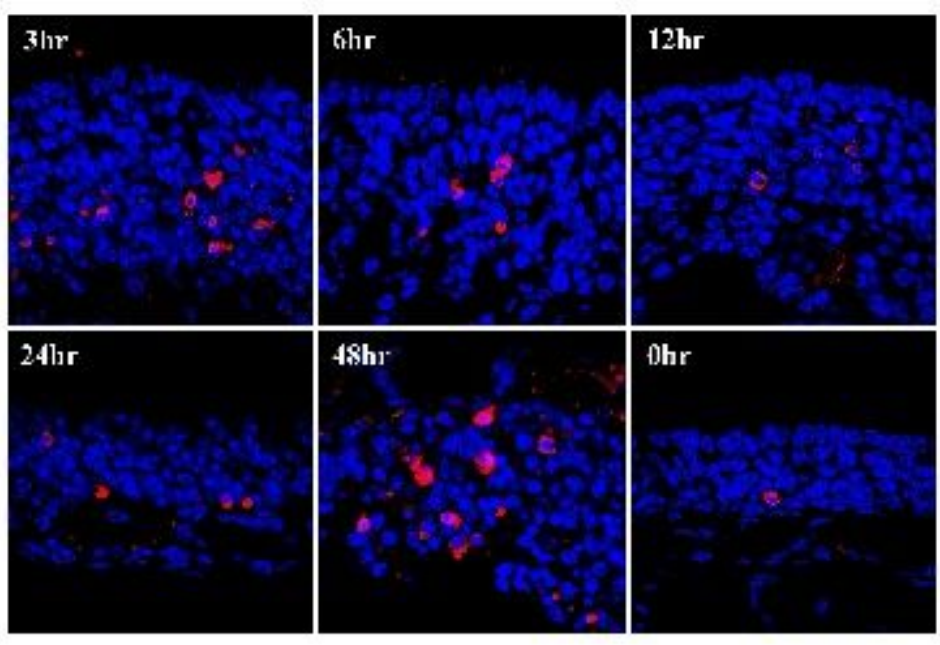

B

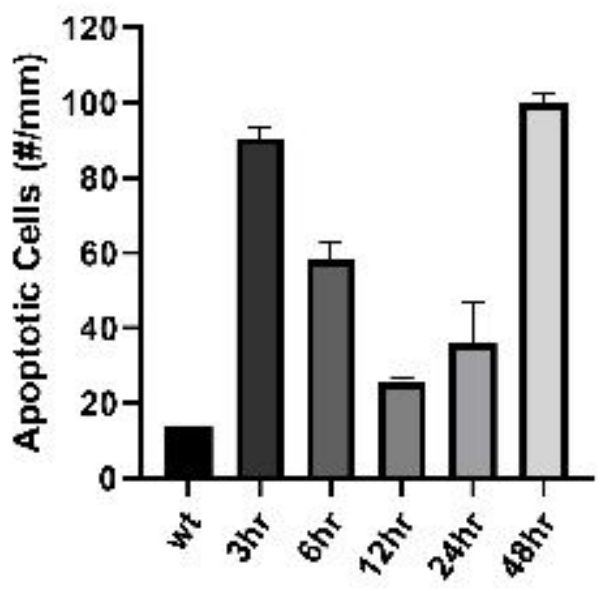

\section{Figure 6}

Viral infection induces apoptosis in the olfactory epithelium. Activated Caspase-3 positive apoptotic cells in the $\mathrm{OE}$ at $0 \mathrm{hr}, 3 \mathrm{hr}, 6 \mathrm{hr}, 12 \mathrm{hr}, 24 \mathrm{hr}$ and $48 \mathrm{hr}$ post VSV infection (A). Apoptotic cell count per $\mathrm{mm}$ of OE tissue at $3 \mathrm{hr}, 6 \mathrm{hr}, 12 \mathrm{hr}, 24 \mathrm{hr}$ and $48 \mathrm{hrPI}(\mathrm{B})$. Scale bar $=20 \mathrm{um}$. 

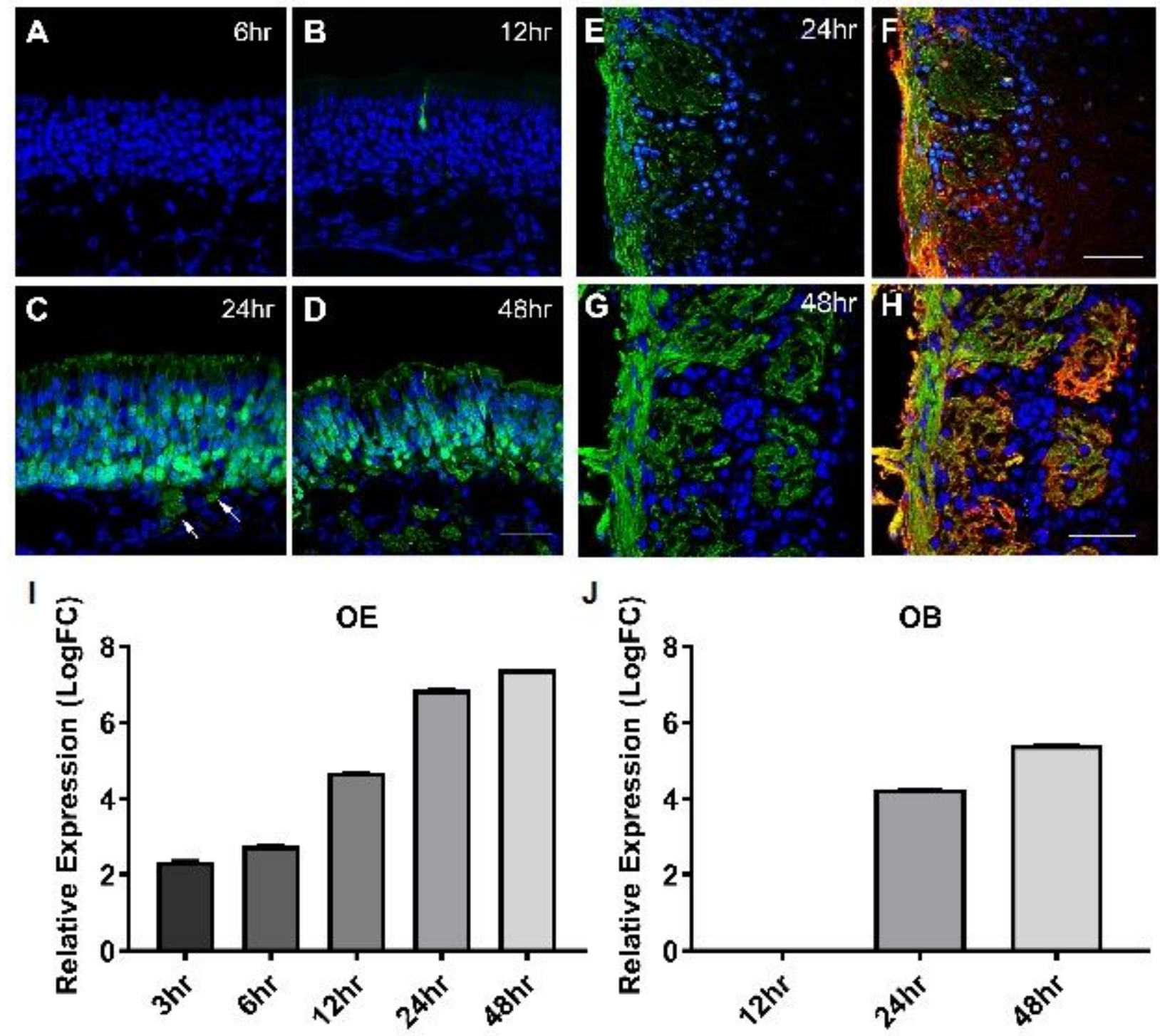

Figure 7

VSVs infect olfactory sensory neurons. Viral-GFP expression in the OE at $6 \mathrm{hr}(\mathrm{A}), 12 \mathrm{hr}(\mathrm{B}), 24 \mathrm{hr}(\mathrm{C})$ and 48hr (D) after VSV12'GFP nasal instillation. Olfactory axons positive for viral-GFP were observed in the lamina propria at 24hr and $48 \mathrm{hrPI}$ (C, D, arrows), as well as in the olfactory nerve layer and glomerular layer of the $\mathrm{OB}(\mathrm{E}-\mathrm{H})$. OMP immunostaining (Red, in $\mathrm{F}, \mathrm{H})$ outlines the distribution of the olfactory axons. Relative expression of viral-GFP transcript in the OE $(\mathrm{I})$ and OB $(\mathrm{J})$ at different time points after viral exposure, determined by qRT-PCR, demonstrates viral load increase in the tissue. Scale bar $=30 \mathrm{um}$ in D and 50um in $\mathrm{F}$ and $\mathrm{H}$. 